\title{
Editorial: Big Earth Data for Disaster Risk Reduction
}

\author{
Fang Chen ${ }^{1,2}$, Umesh K. Haritashya ${ }^{3}$, Mahesh Prakash ${ }^{4}$ and Lei Wang ${ }^{2 *}$ \\ ${ }^{1}$ Key Laboratory of Digital Earth Science, Aerospace Information Research Institute, Chinese Academy of Sciences, Beijing, \\ China, ${ }^{2}$ State Key Laboratory of Remote Sensing Science, Aerospace Information Research Institute, Chinese Academy of \\ Sciences, Beijing, China, ${ }^{3}$ Department of Geology and Environmental Geosciences, College of Arts and Sciences, University of \\ Dayton, Dayton, OH, United States, ${ }^{4}$ CSIRO Data61, Clayton South, VIC, Australia
}

Keywords: big earth data, hazards mapping, digital disaster reduction, remote sensing, disaster data

Editorial on the Research Topic

Big Earth Data for Disaster Risk Reduction

Disasters are becoming increasingly intense and frequent and posing significant threats to life and property-making risk reduction more crucial than ever for achieving regional and local sustainable development goals (SDG) adopted by United Nations and the Sendai Framework for Disaster Risk Reduction (DRR) (2015-2030) [1].

Disaster data at various spatial and temporal scales, such as national, regional and global, is crucial in hazards mapping, disaster risk modeling, disaster loss compensation, disaster loss accounting, etc. It also links science-based assessment to aid policy development for DRR. However, in the past availability of such data has often been the most limiting factor in DRR studies [2,3]. With the rapid development of smart sensors, social networks, digital maps, and remotely-sensed imagery, spatiotemporal disaster data are becoming widely available and could be effectively applied to risk reduction studies.

Big Earth Data, a type of big data associated with the Earth sciences derived from but not limited

\section{OPEN ACCESS}

Edited and reviewed by: Carmine Galasso,

University College London, United Kingdom

*Correspondence:

Lei Wang

wanglei@radi.ac.cn

Specialty section: This article was submitted to Geohazards and Georisks, a section of the journal Frontiers in Earth Science

Received: 18 June 2021 Accepted: 24 June 2021 Published: 06 July 2021

Citation: Chen F, Haritashya UK, Prakash M and Wang L (2021) Editorial: Big Earth Data for Disaster Risk Reduction. Front. Earth Sci. 9:727547. doi: 10.3389/feart.2021.727547 to Earth observation, is becoming a new frontier in contributing to the advancement of Earth science and significant scientific discoveries [4, 5]. Satellite based spatial data and technologies, especially Big Earth Data approaches, are an essential tool for improving our understanding of disaster risks and for coordinated efforts to reduce climate change related disasters and sustainable development [6].

However, the availability of such large datasets (big data) also poses challenges in data management and analysis [7]. It is clear that in the future, we will have more high-quality and large-scale repetitive, yet very little attention has been paid to efficiently managing and using them for DRR. Therefore, this special issue focusses on improving knowledge on DDR with Big Earth Data. Five contributions were accepted after the peer review process covering three primary components: 1) Web services accessibility (i.e., seismological web services), 2) Exposure elements transformed into spatial data (i.e., flash flood hazards), 3) Application in DRR (i.e., landslides and wildfire). We hope that this special issue provides useful new insights into each of these aspects.

\section{WEB SERVICES ACCESSIBILITY}

Though web services can provide convenient access to seismological data, the complexity of the discipline-specific data encodings and the lack of unified standard of seismological web services always make new web services unavailable to users. Locati et al. [8] introduces "QQuake," a plugin for Open Source QGIS code available on GitHub. It is designed in a modular and customizable way and allows users easier access to seismological data. 


\section{EXPOSURE ELEMENTS TRANSFORMED INTO SPATIAL DATA}

In the era of big data and hyper-connectivity, the availability of open-access data on exposure elements across scales and systems is largely unknown. When available it generally is very poor in disaster databases coverage and not useful for local scale application. Muhamad et al. developed an exposure element data inventory of flashflood hazards in Kuala Lumpur, Malaysia, by transforming multiple open data sources within the national system into spatial data. The exposure elements dataset benefits decision-making when overlain with existing flood hazard zones and susceptible areas and has great potential to advance information sharing on disaster and climate risks in the region.

\section{APPLICATION IN DISASTER RISK REDUCTION}

Landslides cause thousands of casualties and substantial socioeconomic impacts around the world every year $[9,10]$. Many landslide parameters and increasingly sophisticated statistical methods have been used in landslide research over the past decades [11]. However, poor representation of actual ground conditions hampers research results to be applied in practice [12]. Daniel et al. conducted a landslide susceptibility assessment with the bivariate statistical method, which reduces the number of input parameters from 13 to 6 . It includes an iterative process of expert consultation by adding the planar failure potential parameter. This approach improved the quality of the landslide inventory and delineated key conditioning parameters. The resultant map captures local conditions that are very useful for landslide management. For landslides susceptibility assessment, many landslide models have been developed at local and regional scales, but very few have characterized landslide hazards at a global scale. In order to better understand the landslide susceptibility at the global scale, the

\section{REFERENCES}

1. United Nations (2015). Sendai Framework for Disaster Risk Reduction 20152030. Geneva, Switzerland: United Nations Office for Disaster Risk Reduction.

2. Huggel, C., Raissig, A., Rohrer, M., Romero, G., Diaz, A., and Salzmann, N. (2015). How Useful and Reliable Are Disaster Databases in the Context of Climate and Global Change? A Comparative Case Study Analysis in Peru. Nat. Hazards Earth Syst. Sci. 15 (3), 475-485. doi:10.5194/nhess-15-475-2015

3. Li, G., Zhao, J., Murray, V., Song, C., and Zhang, L. (2019). Gap Analysis on Open Data Interconnectivity for Disaster Risk Research. Geo-Spatial Inf. Sci. 22 (1), 45-58. doi:10.1080/10095020.2018.1560056

4. Guo, H., Chen, F., Sun, Z., Liu, J., and Liang, D. (2021). Big Earth Data: a Practice of Sustainability Science to Achieve the Sustainable Development Goals. Sci. Bull. 66 (11), 1050-1053. doi:10.1016/j.scib.2021.01.012

5. Guo, H. (2018). Steps to the Digital Silk Road. Nature 554 (7690), 25-27. doi:10.1038/d41586-018-01303-y

6. Chen, F., Zhang, M., Guo, H., Allen, S., Kargel, J. S., Haritashya, U. K., et al. (2021). Annual 30 M Dataset for Glacial Lakes in High Mountain Asia from 2008 to 2017. Earth Syst. Sci. Data 13 (2), 741-766. doi:10.5194/essd-13-741-2021
Landslide Hazard Assessment for Situational Awareness (LHASA) model was developed [13] and modified (Stanley et al.). The probabilistic outputs calculated by the modified LHASA version allow users to directly manage the trade-off between false negatives and false positives, which make the nowcast useful for a greater variety of geographic settings and applications. The modified LHASA version provides a nearly real-time view of global landslide hazards for a variety of stakeholders.

In the wildfire risk reduction study, Shirazi, et al. developed a machine learning workflow process for South East China to monitor fire risks over a large region by learning from a grid file database containing a time series of several of the important environmental parameters largely extracted from remote sensing data products, and highlight areas as fire risk or non-fire risk over a couple of weeks in the future. They found that the model showed a better representation of mixed forest in the training samples as compared to others.

\section{AUTHOR CONTRIBUTIONS}

All authors listed have made a substantial, direct, and intellectual contribution to the work and approved it for publication.

\section{FUNDING}

This research was funded by National Key R\&D Program of China, grant number 2019YFD1100803.

\section{ACKNOWLEDGMENTS}

We thank all contributors for submitting their work in this special issue, the reviewers for their time and effort, and the entire Frontiers team for their support throughout the conception and design of the special issue.

7. Wang, N., Chen, F., Yu, B., and Qin, Y. (2020). Segmentation of Large-Scale Remotely Sensed Images on a Spark Platform: A Strategy for Handling Massive Image Tiles with the MapReduce Model. ISPRS J. Photogrammetry Remote Sensing 162, 137-147. doi:10.1016/j.isprsjprs.2020.02.012

8. Locati, M., Vallone, R., Ghetta, M., and Dawson, N. (2021). QQuake, a QGIS Plugin for Loading Seismological Data from Web Services. Front. Earth Sci. 9 (11). doi:10.3389/feart.2021.614663

9. Froude, M. J., and Petley, D. N. (2018). Global Fatal Landslide Occurrence from 2004 to 2016. Nat. Hazards Earth Syst. Sci. 18 (8), 2161-2181. doi:10.5194/nhess-18-2161-2018

10. Stanley, T., Kirschbaum, D., and Zhou, Y. (2015). Spatial and Temporal Analysis of a Global Landslide Catalog. Geomorphol. 249 (NOV.15), 4-15. doi:10.1016/j.geomorph.2015.03.016

11. Yu, B., Chen, F., and Xu, C. (2020). Landslide Detection Based on ContourBased Deep Learning Framework in Case of National Scale of Nepal in 2015 ScienceDirect. Comput. Geosciences 135, 10438. doi:10.1016/ j.cageo.2019.104388

12. Hearn, G. J., and Hart, A. B. (2019). Landslide Susceptibility Mapping: a Practitioner's View. Bull. Eng. Geol. Environ. 78 (8), 5811-5826. doi:10.1007/ s10064-019-01506-1 
13. Kirschbaum, D., and Stanley, T. (2018). Satellite-Based Assessment of RainfallTriggered Landslide Hazard for Situational Awareness. Earth's Future 6 (3), 505-523. doi:10.1002/2017ef000715

Conflict of Interest: The authors declare that the research was conducted in the absence of any commercial or financial relationships that could be construed as a potential conflict of interest.
Copyright (c) 2021 Chen, Haritashya, Prakash and Wang. This is an open-access article distributed under the terms of the Creative Commons Attribution License (CC $B Y$ ). The use, distribution or reproduction in other forums is permitted, provided the original author(s) and the copyright owner(s) are credited and that the original publication in this journal is cited, in accordance with accepted academic practice. No use, distribution or reproduction is permitted which does not comply with these terms. 